\title{
Bean production and fusarium root rot in diverse soil environments in Iran
}

\author{
B. Naseri \\ Department of Plant Protection, Agricultural \& Natural Resource Research Center, Kermanshah, Iran. Corresponding author: \\ bitanaseri@yahoo.com
}

\begin{abstract}
The associations of Fusarium root rot (FRR) and yield variables with a number of soil characteristics were determined at pod maturity in 122 commercial bean fields in Zanjan, Iran. Mean pod and seed numbers per plant at a sand content level of $45-65 \%$ were lower than those at a level of $25-45 \%$. Higher FRR index and fewer pods were detected in field soils with 30-48\% silt content compared to $15-30 \%$ level. FRR index was higher in field soils treated with fungicides compared to non-treated soils. The lowest FRR index and highest yields occurred in the soils with the highest level of organic matter, 1.2-1.8\%. The greatest FRR index and lowest yield levels were observed in non-nodulated beans compared to low- and high-nodulated beans. Soil $\mathrm{pH}$ and organic matter were negatively correlated with FRR variables. According to loadings for second principal component, the most relevant soil characteristic to FRR was $\mathrm{pH}$, followed by organic matter, clay and sand content. There were spatial FRR correlations among bean fields. Organic matter was the most effective factor among the soil properties surveyed to improve bean productivity. This new information extends our knowledge over interactions between FRR, yield and various soil variables in commercial bean fields.
\end{abstract}

Keywords: Fusarium solani, common bean, principal component analysis, soil texture

\section{Introduction}

The common or dry bean (Phaseolus vulgaris L.) is an important crop worldwide. Root rots have been frequently reported as major threats to bean crops in northeast Brazil, Mexico, Nicaragua, coastal Peru, and the United States (Abawi, 1989). Fusarium root rot (FRR) disease, caused predominantly by F. solani f. sp. phaseoli (FSP), threatens bean production in Zanjan province, north-western Iran (Naseri, 2008). Favourable environmental conditions in particular soil properties have possibly caused FRR to become well established in the main bean growing region of the province in the last few years compared to the mid1990s when FRR rarely occurred in commercial fields (Naseri, 2008). It is expected that FRR still has potential to spread further and adversely influence bean yield if appropriate soil conditions continue. It is known that FSP infects bean root by mycelial growth derived from chlamydospores in the soil where the fungus survives for long periods of time (Kraft et al., 1981). Thus, epidemics of soil-borne diseases, 
such as FRR, depend on interactions between the disease development and soil environment (Otten and Gilligan, 2006). For example, providing a soil environment appropriate to antagonistic and saprophytic microbial activities can protect bean crops from root rot pathogens and stresses (Buerkert et al., 1990; Tu, 1992). Thus, the large-scale evaluation of various soil factors linked to FRR and yield could provide useful information, which may assist with the improvement of productivity through maximizing stress on FSP and minimizing stress on bean.

Naseri (2008) reported remarkable differences in the disease incidence, severity, index, and yield loss to bean root rots among commercial fields of Zanjan. It was suggested that the use of 100 -seed weight might be inappropriate for estimating yield loss from root rot diseases when bean varieties differ in seed size. Later, Naseri and Marefat (2011) found that agronomic practices such as crop planted before bean, irrigation frequency, urea application rate, date and depth of sowing accounted for a considerable part of FRR variability among bean fields. Of the agronomic and FRR factors surveyed, only bean market class (pinto, red, white), FRR severity, plant and weed density, and seeding depth affected pod and seed production. In addition to agricultural factors and genetic diversity in FSP populations (Khodagholi et al., 2011), information on the regional effects of soil characteristics responsible for the differences in FRR and yield will benefit fieldscale approaches to minimize FRR risks to bean crops. Although soil $\mathrm{pH}$, organic materials, texture, root-colonizing bacteria and pests such as bean fly (Ophiomyia spp.) are known to influence FRR (Kraft et al., 1981; Letourneau and Msuku, 1992; Ghorbani et al., 2008), the regional assessment of bean yield and FRR in interaction with soil factors is little understood. While there are many documented soil studies on using principal component analysis (PCA) to select a subset from a large data set, the use of this statistical tool to obtain an overview of the regional data on soil properties affecting various pathosystems has received no consideration. In Zanjan, native root-colonizing bacteria identified as Rhizobium sp., significantly reduced FRR and enhanced bean yield in Rhizobiuminfected plants compared to Rhizobium-free plants under greenhouse conditions (Kalantari et al., 2011). This apparent link represented the basis of this idea to explore whether rhizobial nodulation is linked to FRR restriction and production improvement in commercial bean fields. Moreover, information on the status of fly damage, soil organic matter content and treatment of soil with various fungicides across the area and in relation to FRR and bean yield will help to make management decisions to reduce FRR. Local growers were surprised how strongly soil texture and $\mathrm{pH}$ interact with FRR establishment and bean production at large-scale (Naseri, unpublished). For all the abovementioned reasons, the present work focused on understanding associations of FRR and bean yield with a manageable number of soil biological, chemical and physical properties under environmental conditions in commercial fields of Zanjan. One of the major interests in soil analysis was the integrated evaluation of the soil properties, which might be indicators of FRR spread across bean fields. Thus, a PCA was used to choose variables best representing the establishment of FRR in various soil environments.

\section{Materials and Methods}

\subsection{Epidemiological surveys}

The study area was located in the main bean growing region of Zanjan province between longitudes $48^{\circ} 20^{\prime}-$ $49^{\circ} 30^{\prime} \mathrm{W}$ to $\mathrm{E}$ and latitudes $36^{\circ}-36^{\circ} 40^{\prime} \mathrm{S}$ to $\mathrm{N}$. The normal growing period of bean in Zanjan involves sowing in mid to late spring (May-June) and harvesting in late summer (September). 122 common bean fields ranging from 0.5 to 14 ha in size were randomly selected from a total number of 1452 bean fields across the region from 2008 to 2009 (35 in 2008 and 87 in 2009). In the region studied, beans are normally rotated with wheat, bean, alfalfa, barley, maize, potato, and tomato. In the current study, in $57 \%$ of the fields wheat was the previous crop. Bean growers were asked whether they 
treated the soil and seed with fungicides. It was also difficult to detect the length of irrigation period and the amount of water supplied with flood irrigation system (except for three fields with sprinkler irrigation) to the fields. Fields were examined for FRR incidence and severity, bean fly infestation, and rhizobial nodulation on roots at pod maturity (growth stage R9; Van Schoonhoven and Pastor-Corrales, 1987). In each field, disease incidence (percentage of plants showing symptoms of leaf chlorosis, wilt, yellowing or death) was assessed at three randomly selected spots of $0.25 \mathrm{~m} 2$, i.e. about 6 plants. Then three plants per quadrat were examined for the number of pods and seeds per plant, fly damage, rhizobial nodulation and FRR severity. The status of bean fly damage was described according to the presence or absence of puparia infestations (typical holes, ca $0.5 \mathrm{~mm}$ diameter) on tap roots. The status of rhizobial nodulation on root system was assessed using a scale modified from that of Van Schoonhoven and Pastor-Corrales (1987): $0=$ no nodulation, $1=$ low to medium nodulation with 1-3 small $(<1 \mathrm{~mm}$ diameter) nodules, and $2=$ high nodulation with more than four well-developed ( $>1 \mathrm{~mm}$ diameter) nodules per rootlet. The disease severity was rated using the $0-5$ scale based on the percentage of root tissues with discolouration, red streaks, or rots (Naseri, 2008). For each quadrat, a root disease index was also calculated as follows: disease incidence $\times$ disease severity/ 5 (Naseri, 2008). The disease incidence was determined by measuring the proportion of plants affected by FRR. The complete details on confirmation of FSP infection and pathogenicity tests were provided by Naseri (2008) and Naseri and Marefat (2011).

At vegetative stage, field soils (one sample ca $1 \mathrm{~kg}$ per quadrat) were sampled and analyzed according to standard methods (Jackson, 1958; Bouyoucos, 1962) as Naseri (2013) described previously. The mean monthly temperature and total monthly rainfall throughout the growing seasons were obtained from the weather station located at Kheirabad $\left(36^{\circ} 30^{\prime} \mathrm{N}\right.$, $48^{\circ} 47^{\prime} \mathrm{E}, 1770 \mathrm{~m}$ a.s.1.).
2.2. Categorization of bean fields according to soil factors

After a preliminary analysis, the information obtained from the field assessments and the farmers was used to categorize the fields according to the soil factors to determine the effect of the factors on FRR and yield (Table 1). Considering USDA classification scheme for soil textural analysis (Gee and Bauder, 1986), three and two ranges were selected for the clay, sand and silt content of field soils, respectively. Fields were categorized into the two groups, based on whether field soil was treated with a fungicide (yes = $1)$ or not $($ no $=0)$. Based on the data collected, fields were grouped to three levels of nodulation, three organic matter contents, two $\mathrm{pH}$ ranges, two levels of fly infestation and two sampling years (Table 1).

\subsection{Statistical analysis}

Data on FRR index, and pod and seed numbers per bean plant collected from 122 bean fields were analyzed using linear mixed modeling with the method of residual maximum likelihood (REML) implemented in GENSTAT version 6.1 (Lawes Agricultural Trust, Rothamsted Experimental Station, UK). Clay, sand and silt content of soil, fungicide usage, organic matter, $\mathrm{pH}$, rhizobial nodulation and fly infestation in interaction with the sampling year were used as fixed terms. The form of the random part of the mixed model was Field/Replicate. The standard error of difference (SED) test $(p=0.05)$ was used for pair-wise comparisons of means. All percentage values for disease incidence and index were arcsine square root transformed before further statistical analysis to improve the homogeneity of the variance of the data. The appropriateness of the transformation was evaluated by the examinations of the pattern of the residuals plots. Due to unequal number of fields at different levels of factors, REML and Wald tests (GENSTAT) were used to examine the effects of factors. Relationships between FRR, yield and soil variables were analysed with a simple linear regression (GENSTAT). The criteria used to evaluate 
the strength of regressions were the coefficient of correlation (r) and the $P$ value.

In principal components analysis, principal components (PCs) for a data set are defined as linear combinations of the variables that account for maximum variance within the data. It was assumed that $\mathrm{PCs}$ receiving high percentage variances best represent variation in the soil properties among the fields. Correlations of FRR with PCs were examined using simple linear regression (GENSTAT). Under a considered PC, each variable is given a loading that describes the contribution of that variable to component composition. One-dimensional FRR (severity ratings at R9) data in the form of an irregular grid was analyzed with a spatial mixed modeling using REML (GENSTAT) to determine if there is spatial FRR correlations among the fields surveyed. Field and replicate formed the fixed and the random models, respectively.

\section{Results}

Wald tests demonstrated that the sampling year significantly affected the disease index (Table 2). Mean FRR index at R9 differed $(p<0.05)$ between the years of survey, being higher in 2009 (Table 3).
The mean monthly temperature during the growing season was higher in 2008 than in 2009, except for July (Figure 1). The total monthly rainfall for May, June and September was greater in 2009 than in 2008.

The bean fields studied were categorized based on the clay content of the soil as follows: $14-25 \%$ (in $9.8 \%$ of the fields), $25-35 \%$ (46.7\%), and $35-53 \%$ (43.5\%; Table 1). The bean fields studied were categorized into the three classes with respect to the sand content of the soil as follows: $4-25 \%$ (in $21.3 \%$ of the fields), $25-45 \%$ (62.3\%), and 45-65\% (16.4\%; Table 1). Sand content of field soil affected significantly the yield factors examined at R9 (Table 4). Mean pod and seed numbers per plant differed $(p<0.05)$ between the highest and the intermediate level of the sand content in being lower at $45-65 \%$ level (Table 5). The sand content was negatively correlated $(p<0.05)$ with the clay content (Table 6).

The bean fields studied were classified into the two groups with respect to the silt content of the soil as follows: $15-30 \%$ (in $36.9 \%$ of the fields) and $30-48 \%$ (63.1\%; Table 1). The silt content affected FRR index $(p=0.001$; Table 2). Mean FRR index differed $(p<$ 0.05 ) between the levels of silt content, being lower at 15-30\% level (Table 3).

Table 1. The number of common bean fields (122 in total) with different soil conditions categorized into levels according to characteristics surveyed, 2008-2009

\begin{tabular}{llcl}
\hline Factors & \multicolumn{3}{c}{ Factor levels/No. of fields } \\
\hline Clay $\%$ & $14-25 / 12$ & $25-35 / 57$ & $35-53 / 53$ \\
Sand $\%$ & $4-25 / 26$ & $25-45 / 76$ & $45-65 / 20$ \\
Silt $\%$ & $15-30 / 45$ & & $30-48 / 77$ \\
Fly infestation & No/101 & & Yes $/ 21$ \\
Fungicide use & No/106 & & Yes/16 \\
Nodulation & $0 / 43$ & Low/64 & High/15 \\
Organic matter & $0.4-0.8 / 39$ & $0.8-1.2 / 71$ & $1.2-1.8 / 12$ \\
pH & $7.0-7.5 / 86$ & & $7.5-7.9 / 36$ \\
Year & $2008 / 35$ & & $2009 / 87$ \\
\hline
\end{tabular}


Table 2. Effects of soil factors on index of Fusarium root rot assessed at growth stage R9 in bean fields, 2008-2009

\begin{tabular}{|c|c|c|c|c|c|c|c|}
\hline \multirow{2}{*}{$\begin{array}{l}\text { Factor } \\
\text { Fixed term } \\
\end{array}$} & \multicolumn{3}{|c|}{ Disease index } & \multirow{2}{*}{$\begin{array}{c}\text { Factor } \\
\text { Fixed term } \\
\end{array}$} & \multicolumn{3}{|c|}{ Disease index } \\
\hline & Wald statistic & df & Chip & & Wald statistic & df & Chip \\
\hline Clay & 1.3 & 2 & 0.522 & Clay.Year & 3.5 & 2 & 0.17 \\
\hline Sand & 0.5 & 2 & 0.775 & Sand.Year & 3.8 & 2 & 0.149 \\
\hline Silt & 543.0 & 2 & 0.001 & Silt.Year & 0.6 & 1 & 0.45 \\
\hline Fly & 0.2 & 1 & 0.643 & Fly.Year & 5.2 & 1 & 0.071 \\
\hline Fungicide use & 4.1 & 1 & 0.044 & Fungicide.Year & 0.1 & 1 & 0.727 \\
\hline Nodulation & 10.8 & 2 & 0.004 & Nodulation.Year & 4.0 & 2 & 0.139 \\
\hline Organic matter & 15.1 & 2 & 0.001 & Organic.Year & 1.2 & 2 & 0.563 \\
\hline $\mathrm{pH}$ & 2.4 & 1 & 0.123 & pH.Year & 0.0 & 1 & 0.895 \\
\hline Year & 20.0 & 1 & 0.001 & & & & \\
\hline
\end{tabular}

Table 3. Index of Fusarium root rot at different levels of soil factors assessed at growth stage R9 in bean fields, 2008-2009

\begin{tabular}{lccc}
\hline Factors $^{\mathrm{a}}$ & & Factor levels & \\
\hline Fungicide use & No & & Yes \\
SED $=7.9$ & $29.4^{\mathrm{b}}\left(26.1^{\mathrm{c}}\right)$ & & $37.4(41.4)$ \\
\hline Nodulation & 0 & Low & High \\
$\mathrm{SED}=6.6$ & $38.0(42.5)$ & $30.8(28.4)$ & $26.6(21.4)$ \\
\hline Organic matter & $0.4-0.8$ & $0.8-1.2$ & $1.2-1.8$ \\
$\mathrm{SED}=7.0$ & $44.0(55.6)$ & $33.5(33.6)$ & $17.8(9.7)$ \\
\hline Silt & $15-30 \%$ & & $30-48 \%$ \\
$\mathrm{SED}=6.0$ & $27.0(21.9)$ & & $36.6(39.7)$ \\
\hline Year & 2008 & & 2009 \\
SED $=11.5$ & $11.1(3.8)$ & & $52.4(74.3)$ \\
\hline
\end{tabular}

${ }^{\mathrm{a}}$ Only factors with significant effects are presented. ${ }^{\mathrm{b}}$ Arcsine-transformed means of disease index. ${ }^{\mathrm{c}}$ Back-transformed means.
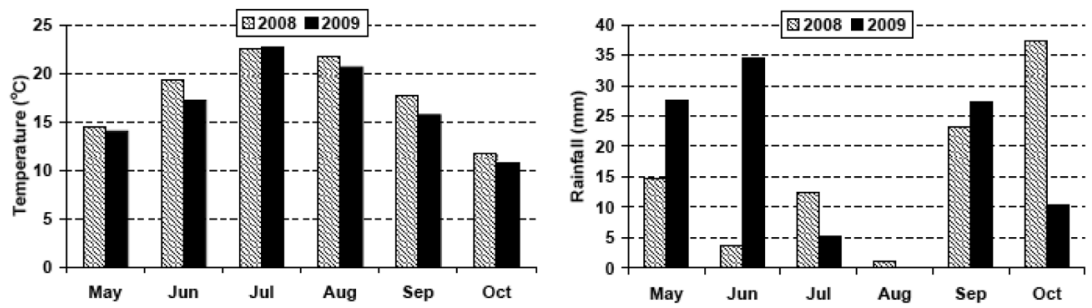

Figure 1. Mean monthly temperature and total monthly rainfall obtained during growing season, 2008-2009. 
The two-way interaction of the silt content with the sampling year affected the number of pods per plant $(P=0.028$; Table 4). In 2008, there was a significant difference in the mean number of pods per plant between the levels of silt content, the yield value being higher at $15-30 \%$ level (Table 5). The silt content was correlated $(p<0.05)$ with the clay and the sand content (Table 6).

Damage by fly puparia was evident in $17.2 \%$ of the fields surveyed at R9 (Table 1). Of the 122 fields studied, the soil was treated with fungicides in 16 (13.1\%) fields (Table 1). The most common fungicide used was benomyl (in $62.5 \%$ of the treated fields), followed by mancozeb and metalaxyl (recommended by local experts). The application of fungicide affected significantly the disease index (Table 2). The mean FRR index at R9 differed significantly between the treated and non-treated field soils in being higher for fungicide usage (Table 3).

The majority $(70.5 \%)$ of the fields were categorized into the low range of $\mathrm{pH}$ (7-7.5; Table 1). Soil $\mathrm{pH}$ was negatively correlated $(p<0.05)$ with FRR severity and index (Table 6).

Common bean fields studied were grouped into the three classes with respect to the organic matter content of the soil as follows: $0.4-0.8 \%$ (in $32 \%$ of the fields), 0.8-1.2 (58.2\%), and 1.2-1.8 (9.8\%; Table 1 ). The status of soil organic matter was significantly effective on FRR index (Table 2). The mean FRR index differed significantly among the classes of organic matter content (Table 3). The disease index for the lowest range of organic matter was 2.5 times greater $(p<0.05)$ than the corresponding value for the highest range. Soil organic matter also affected $(p=0.001)$ the yield parameters examined (Table 4$)$. The organicmatter $\times$ year interaction affected the number of pods per plant $(P=0.023)$. In both of the sampling years, the mean number of pods per plant differed significantly between the levels of organic matter content, except for the lowest level in 2009 (Table 5). The mean seed numbers per plant for organic matter ranging from
0.4 to 1.2 was lower $(p<0.05)$ by nearly half of the corresponding value for the highest level $1.2-1.8 \%$. The organic matter content was correlated with the FRR (negative), sand (negative), silt (positive) and yield (positive) variables (Table 6).

Classification of the bean fields into the three levels of rhizobial nodulation was as follows: no nodulation (in $35.2 \%$ of the fields), low nodulation (52.5\%), and high nodulation (12.3\%; Table 1). The status of root nodulation affected $(P=0.004)$ FRR index (Table 2 ). The mean FRR index for nodulated beans was significantly different from that for non-nodulated beans, being higher for no nodulation (Table 3). The nodulation $\times$ year interaction affected the number of pods $(P=0.023)$ and seeds $(P=0.013)$ per plant. In 2008 , mean pod and seed numbers per plant differed $(p$ $<0.05$ ) between the categories of the nodulation factor in being greater at the intermediate level (Table 5). In 2009 , the mean seed numbers per plant differed $(p<$ 0.05 ) between high- and low-nodulated beans in being lower for low nodulation.

The quantitative soil variables, clay, sand, silt, organic matter and $\mathrm{pH}$, were included for the PCA. Using correlation matrix, it was found that the first four PCs accounted for $100 \%$ of the variance of the data obtained in 2008 and 2009 (Table 7). First PC explained $53 \%$ of total variance with sand content as the major contributing variable (loading $=0.60$ ). Second PC accounted for a further $21 \%$ of total variance with $\mathrm{pH}$ as the major contributing variable (loading $=-0.76$ ). Major contributing variables were organic matter (loading $=-0.67$ ) in the third PC and silt content (loading $=0.73$ ) in the fourth PC. None of the components separated 2008-examined fields from 2008-examined ones (data not shown). Similarly, there was no good separation between the levels of fungicide use and nodulation factors (data not shown). The second component was correlated $(\mathrm{r}=0.29 ; P=$ 0.001 ) with FRR index. PC2 contrasted the clay content (loading $=0.24$ ) with soil organic matter (loading $=-0.59$ ), $\mathrm{pH}$ (loading $=-0.76$ ), and sand (loading = -0.16). REML analysis demonstrated that the spatial 
model was fitted to FRR severity ratings detected in the fields (Figure 2). There were correlations among the fields in the same grid (spatial clusters; SED $=0.4$; $p>0.05)$ due to their spatial proximity. For example, fields $63,81,98,106-111,113,116$ and 118 are located in the same grid, forming a severe FRR spatial cluster.

Table 4. Effects of soil factors on bean yield assessed at growth stage R9 in the fields, 2008-2009

\begin{tabular}{|c|c|c|c|c|c|c|}
\hline \multirow{2}{*}{$\begin{array}{l}\text { Factors } \\
\text { Fixed terms }\end{array}$} & \multicolumn{3}{|c|}{ Pods no. per plant } & \multicolumn{3}{|c|}{ Seeds no. per plant } \\
\hline & Wald statistic & $\mathrm{df}$ & Chip & Wald statistic & $\mathrm{df}$ & Chi p \\
\hline$\overline{\text { Clay }}$ & 0.4 & 2 & 0.82 & 0.4 & 2 & 0.805 \\
\hline Sand & 361.5 & 3 & 0.001 & 232.2 & 3 & 0.001 \\
\hline Silt & 1.0 & 1 & 0.325 & 1.3 & 1 & 0.261 \\
\hline Fly & 1.3 & 1 & 0.26 & 1.8 & 1 & 0.185 \\
\hline Fungicide use & 0.8 & 1 & 0.379 & 0.5 & 1 & 0.478 \\
\hline Nodulation & 0.5 & 2 & 0.776 & 0.5 & 2 & 0.762 \\
\hline Organic matter & 15.3 & 2 & 0.001 & 15.8 & 2 & 0.001 \\
\hline $\mathrm{pH}$ & 2.2 & 1 & 0.135 & 2.1 & 1 & 0.146 \\
\hline Year & 0.6 & 1 & 0.448 & 2.0 & 1 & 0.163 \\
\hline Clay.Year & 4.3 & 2 & 0.115 & 4.3 & 2 & 0.118 \\
\hline Sand.Year & 0.2 & 2 & 0.924 & 0.3 & 2 & 0.872 \\
\hline Silt.Year & 4.8 & 1 & 0.028 & 2.7 & 1 & 0.104 \\
\hline Fly.Year & 1.1 & 1 & 0.306 & 0.5 & 1 & 0.479 \\
\hline Fungicide.Year & 0.0 & 1 & 0.926 & 0.0 & 1 & 0.876 \\
\hline Nodulation.Year & 7.5 & 2 & 0.023 & 8.7 & 2 & 0.013 \\
\hline Organic.Year & 7.6 & 2 & 0.023 & 5.5 & 2 & 0.065 \\
\hline pH.Year & 0.3 & 1 & 0.597 & 0.1 & 1 & 0.774 \\
\hline
\end{tabular}

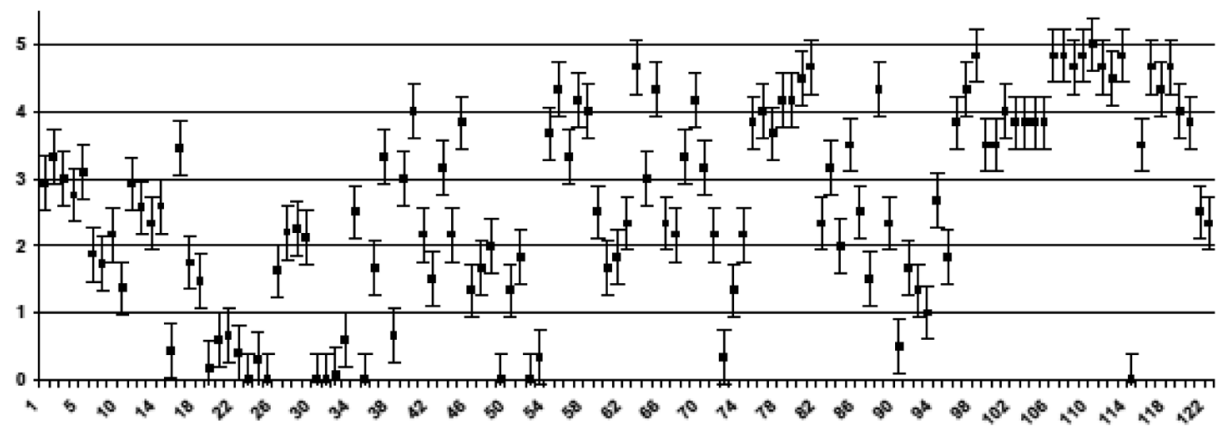

Figure 2. Spatial model of Fusarium root rot (severity ratings; $Y$ axis) examined at pod maturity stage of bean growth in 122 commercial fields (X axis). Bars represent $\mathrm{SED}=0.4$. 
Table 5. Pod and seed numbers per plant at different levels of soil factors assessed at growth stage R9 in bean fields, 2008-2009

\begin{tabular}{|c|c|c|c|c|}
\hline \multicolumn{2}{|l|}{ Factors $^{\mathrm{a}}$} & \multicolumn{3}{|c|}{ Factor levels } \\
\hline Sand & & $4-25 \%$ & $25-45 \%$ & $45-65 \%$ \\
\hline Pod no./Plant $\left(4.6^{\mathrm{b}}\right)$ & & 18.9 & 20.7 & 15.0 \\
\hline Seed no./Plant $\left(21.0^{\mathrm{b}}\right)$ & & 72.9 & 83.4 & 55.4 \\
\hline Organic matter & & $0.4-0.8$ & $0.8-1.2$ & $1.2-1.8$ \\
\hline Pod no./Plant (3.3) & & 13.6 & 14.3 & 26.7 \\
\hline Seed no./Plant (15.3) & & 50.6 & 52.5 & 108.6 \\
\hline Nodulation.Year & & 0 & Low & High \\
\hline \multirow[t]{2}{*}{ Pod no./Plant (5.6) } & 2008 & 13.6 & 26.2 & 11.2 \\
\hline & 2009 & 18.2 & 17.6 & 22.5 \\
\hline \multirow[t]{2}{*}{ Seed no./Plant (25.5) } & 2008 & 47.2 & 107.2 & 39.6 \\
\hline & 2009 & 71.6 & 65.6 & 92.1 \\
\hline Organic matter.Year & & $0.4-0.8$ & $0.8-1.2$ & $1.2-1.8$ \\
\hline \multirow[t]{2}{*}{ Pod no./Plant (5.9) } & 2008 & 7.6 & 13.8 & 29.5 \\
\hline & 2009 & 19.6 & 14.8 & 23.9 \\
\hline Silt.Year & & $15-30 \%$ & & $30-48 \%$ \\
\hline \multirow[t]{2}{*}{ Pod no./Plant (5.4) } & 2008 & 23.5 & & 10.5 \\
\hline & 2009 & 19.8 & & 19.1 \\
\hline
\end{tabular}

${ }^{a}$ Only factors with significant effects are presented. ${ }^{\mathrm{b}}$ SED values between means of pod and seed numbers per plant.

Table 6. Correlations among Fusarium root rot, soil and yield variables examined at growth stage R9 in bean fields, 2008-2009

\begin{tabular}{|c|c|c|c|c|c|c|c|c|c|c|}
\hline & Incidence & Severity & Index & Pod & Seed & Clay & Sand & Silt & $\mathrm{OM}$ & $\mathrm{pH}$ \\
\hline Incidence & $1.00^{\mathrm{a}}$ & & & & & & & & & \\
\hline Severity & $0.91 *$ & 1.00 & & & & & & & & \\
\hline Index & $0.93 *$ & $0.99 *$ & 1.00 & & & & & & & \\
\hline Pod & $-0.44^{*}$ & $-0.41^{*}$ & $-0.43^{*}$ & 1.00 & & & & & & \\
\hline Seed & $-0.44 *$ & $-0.40 *$ & $-0.42 *$ & $0.96^{*}$ & 1.00 & & & & & \\
\hline Clay & -0.09 & -0.10 & -0.10 & -0.08 & -0.09 & 1.00 & & & & \\
\hline Sand & 0.11 & 0.09 & 0.09 & 0.06 & 0.08 & $-0.91^{*}$ & 1.00 & & & \\
\hline Silt & -0.11 & -0.04 & -0.06 & -0.02 & -0.04 & $0.51^{*}$ & $-0.82 *$ & 1.00 & & \\
\hline $\mathrm{OM}$ & $-0.32 *$ & $-0.23^{*}$ & $-0.25^{*}$ & $0.25^{*}$ & $0.25^{*}$ & 0.12 & $-0.27^{*}$ & $0.40^{*}$ & 1.00 & \\
\hline $\mathrm{pH}$ & -0.16 & $-0.26^{*}$ & $-0.24 *$ & -0.05 & -0.07 & 0.16 & -0.14 & 0.06 & 0.11 & 1.00 \\
\hline
\end{tabular}

a Arcsine-transformed means of disease incidence and index, and means of severity rating, pod and seed numbers per plant in three replicate observations per field were used for correlation analysis; $*=p<0.05$. 
Table 7. Eigenvalue, percentage and cumulative variance explained by principal component (PC) analysis using correlation matrix for bean fields, 2008-2009.

\begin{tabular}{cccc}
\hline PCs & Eigenvalue & Percentage & Cumulative \\
\hline 1 & 2.65 & 52.89 & 52.9 \\
2 & 1.03 & 20.59 & 73.5 \\
3 & 0.94 & 18.79 & 92.3 \\
4 & 0.39 & 7.73 & 100.0 \\
\hline
\end{tabular}

\section{Discussion}

Much of available information on the associations between bean yield, FRR and soil factors is based on studies conducted at the spatial scale of individual fields. It is also useful to evaluate the associations of soil environment with bean yield and FRR on a regional basis, which is highly relevant to commercial production conditions. In the present study, a considerable part of the variability in the FRR and yield levels observed among bean fields corresponded with combinations of the soil factors surveyed. Macro-scale evaluation of impacts of soil compaction, temperature, moisture and fertility on bean-FRR pathosystems was not practical in this study due to inadequate time and equipment for regular monitoring of dynamics of these soil variables. Furthermore, soil chemical variables such as extracted soluble salts, cation exchange capacity (CEC), and concentrations of $\mathrm{P}, \mathrm{Ca}, \mathrm{Mg}, \mathrm{Mn}$, and $\mathrm{Fe}$, which had no consistent association with the severity of soybean disease caused by $F$. solani $\mathrm{f}$. sp. glycines in commercial fields (Scherm et al., 1998), were ignored in this study. Supporting previous reports on most severe FRR in beans sown in cold and moist soils (Burke and Miller, 1983), cooler and moister climatic conditions at sowing and harvest times in 2009 might have increased FRR from 2008 to 2009, which merit further investigation.

Soil texture and structure influence root growth and plant diseases through their effects on water holding capacity, nutrient status, gas exchange (Ghorbani et al., 2008). The incidence and severity of soybean sudden death syndrome, caused by F. solani f.sp. glycines, increased by nearly two- and four-fold, as soil sand increased from 53 to $100 \%$, respectively (Sanogo and Yang, 2001). Elsewhere in Fusarium-infested soils, white beans grew better and yielded more in clay-loam than in sandy loam (Tu, 1992). However, the associations of FRR and bean yield with soil texture components are little documented. This regional study evidenced that higher FRR levels were detected in soils with greater silt content. Furthermore, greater sand and silt contents corresponded with lower yield levels. Definitely, future studies should include examination of tillage, soil compaction and moisture retention which are known to affect the interactions of soil type with FRR and bean yield (Ghorbani et al., 2008).

Earlier findings indicated that FRR incidence was correlated with the presence of bean fly puparia (Letourneau and Msuku, 1992). In the present study, damage from bean flies along with FRR symptoms was evident in $17.2 \%$ of the fields studied. Prevalence of FRR in $82.8 \%$ of the fields, where no bean fly infestation was found, may have weakened the impact of fly damage on FRR development across the region.

Chemical treatments of the soil are mostly ineffective on FRR and do not last long enough to protect adventitious roots at later stages in the season (Abawi, 1989). Benomyl, which inhibits the growth of other beneficial antagonistic fungi such as Trichoderma spp. (Papavizas et al., 1982), allows FSP to grow on agar media and in the soil (Richardson, 1973). This may have partially accounted for the significant role of fungicide application in the early and midseason development of FRR in the bean fields that were treated mainly with benomyl. It appeared that the treatment of soil with fungicides detected in this survey not only increased the level of FRR on bean crops, but also increases cropping expenses without a significant increase in yield.

Liming of acidic soils reduced FRR incidence and severity in the greenhouse ( $\mathrm{Tu}, 1992)$ and improved bean nodulation and yield (Buerkert et al., 1990). 
Elsewhere, bean FRR did not respond to changes in soil $\mathrm{pH}$ under greenhouse and field conditions (Schuerger and Mitchell, 1992). These conflicting results may arise from differences between soil environments. In this study, soil $\mathrm{pH}$ (ranged from 7 to 8) was reversely correlated to FRR severity and index at pod maturity across different soil environments. This new information on the association of such a narrowrange soil $\mathrm{pH}$ with late season development of FRR in bean fields may be of sufficient magnitude to be of value to the bean grower and researcher. Moreover, soil $\mathrm{pH}$ is known to be responsible for the effect of the form of nitrogen (Ghorbani et al., 2008) on disease severity or resistance (Huber and Watson, 1974). The soil-acidifying effect of the ammonium form of $\mathrm{N}$-fertilizers such as urea, which was widely overused by bean-growers in Zanjan (Naseri and Marefat, 2011), can nullify the beneficial effects of alkaline $\mathrm{pH}$ (Sullivan, 2001). Although this may partially justify the lack of a significant effect of soil $\mathrm{pH}$ on the yield components studied, further information on more extensive ranges of soil $\mathrm{pH}$ is required.

Organic matter improves biological and physicochemical properties of soils (Weil and Magdoff, 2004) and thus influences crop productivity and protection from root pathogens (Weller et al., 2002). For example, the applications of green manures in croplands can effectively control FRR (Tu, 1992). Wald tests of a large set of data in this survey revealed that the bean fields with the highest level of organic matter (1.2-1.8) exhibited nearly 50\% lower FRR levels and two-fold higher yields, compared to those at the lowest level (0.4-0.8). This remarkable role of soil organic matter in reducing FRR and improving bean productivity suggests that application of organic matter should be a major factor in soil management programs in bean growing areas like Zanjan, with the level of 1.2-1.8 soil organic matter being detected in only $9.8 \%$ of bean fields. Such new findings along with further information on FRR in soils containing more extensive ranges of organic matter will contribute to improved bean production systems promoting soilsuppressiveness against FRR.
In India, the inoculation of FRR-affected beans with R. leguminosarum reduced FRR severity by $34.3 \%$ and increased plant biomass (Hassan Dar et al., 1997). In Minnesota, the effect of seed inoculations with $R$. leguminosarum on bean yield and FRR severity was dependent on the experimental site and year (Estevez de Jensen et al., 2004). It seems difficult to generalize about bean-FRR-Rhizobium interactions, which vary with differences in microbial species, plant cultivars and soil properties across different geographical areas (Hassan Dar et al., 1997). In this study, the presence of rhizobial nodulation appeared to restrict the establishment of bean FRR at pod maturity stage and increase yield levels under different soil conditions on a regional basis. However, detection of high nodulation in only $12.3 \%$ of the fields may reflect the influence of iron deficiency in restricting legume-rhizobia symbiosis and plant growth (Slatni et al., 2008) that is a major problem in calcareous soils of Zanjan. Definitely, further investigation is required to verify this hypothesis. From a production viewpoint, the present macro-scale findings suggests that enhancing root nodules should be considered as important as planting bean in heavy-textured soils (lower sand and silt) in bean cultivation in Zanjan.

The obtained PCs provided a clear and complete picture of the variance of the soil variables in the fields surveyed. Despite the lack of linkage between the major part of information (PC1, 53\%) and FRR, the disease variations across the area was explained with the help of a smaller part of the total data variance (PC2, 21\%). The variables responsible for this noticeable association (29\%) were ordered as follows: $\mathrm{pH}$, organic matter, clay and sand content of the field soil. The data information from $\mathrm{PC} 2$ can be interpreted as characterizing the bean fields according to soil conditions. These results can be considered remarkable because, although the interrelationships among soil properties was expected, the observed order of soil indicators for FRR development at large scale was not so expected, since so narrow ranges of some soil parameters, e.g. $\mathrm{pH}$, could not be enough to describe FRR changes depending on soil parameters. 


\section{Conclusion}

Many researchers believe that increased pest and disease pressure on various crops is due to changes in cropping systems particularly applications of agrochemicals (Altieri and Nicholls, 2003). According to the recent (Naseri and Marefat, 2011) and present findings, the use of urea and improper fungicides appeared to increase FRR and cropping costs without a significant increase in bean production. On the other hand, organic matter content was the most effective factor among the soil properties surveyed to improve productivity. Further research could identify appropriate organic manures to improve bean yield and reduce agrochemical usage.

\section{Acknowledgements}

This study was supported by the grant from the Iranian Ministry of Agriculture, research project no. 2-4716-87083. The author thanks Mr. J. McNicol for his valuable statisticaladvice, and Mrs. L. Tabande for soil analysis. The author appreciates the cooperation of the many bean growers who were involved in this work.

\section{References}

Abawi, G.S. 1989. Root rot. In: H.F. Schwartz, M.A. Pastor-Corrales (eds). Bean Production Problems: Disease, insect, soil and climatic constraints of Phaseolus vulgaris. Centro Internacional de Agricultura Tropical, Cali, Colombia, pp: 105-57.

Altieri, M.A., Nicholls, C.I. 2003. Soil fertility management and insect pests: harmonizing soil and plant health in agroecosystems. Soil Till. Res. 72, 203-211.

Bouyoucos, C.J. 1962. Hydrometer method improved for making particle size analyses of soils. Agron. J. 54, 464-465.
Buerkert, A., Cassman, K.G., Piedra, R. de la, Munns, D.N. 1990. Soil acidity and liming effects on stand, nodulation and yield of common bean. Agron. J. 82, 749-754.

Burke, D.W., Miller, D. E. 1983. Control of Fusarium root rot with resistant beans and cultural management. Plant Dis. 67, 1312-1317.

Estevez de Jensen, C., Kurle, J.E., Percich, J.A. 2004. Integrated management of edaphic and biotic factors limiting yield of irrigated soybean and dry bean in Minnesota. Field Crops Res. 86, 211-224.

Gee, G.W., Bauder, J.W. 1986. Particle size analysis. In: A. Klute (ed). Methods of Soil Analysis. Part 1. Physical and Mineralogical Methods. Soil Science Society of America Madison, WI, USA, pp: 383-411.

Ghorbani, R., Wilcockson, S., Koocheki, A., Leifert, C. 2008. Soil management for sustainable crop disease control: a review. Environ. Chemist. Lett. 6, 149-162.

Hassan Dar, G., Zargar, M.Y., Beigh, G.M. 1997. Biocontrol of Fusarium Root Rot in the Common Bean (Phaseolus vulgaris L.) by using Symbiotic Glomus mosseae and Rhizobium leguminosarum. Microb. Ecol. 34, 74-80.

Huber, D.M., Watson, R.D. 1974. Nitrogen form and plant disease. Ann. Rev. Phytopathol. 12, 139 165.

Jackson, M.L. 1958. Soil Chemical Analysis. Prentice-Hall, New Jersey.

Kalantari, S., Marefat, A., Naseri, B., Hemati, R. 2011. Biocontrol of bean Fusarium root rot using soil microbia in Zanjan province. The First Congress of Modern Agricultural Sciences and Technologies. Zanjan University, Zanjan, Iran, pp: $240-243$. 
Khodagholi, M., Hemati, R., Naseri, B., Marefat, A. 2011. Genetic diversity of Fusarium solani, causing bean Fusarium root rot in Zanjan province. The First Congress of Modern Agricultural Sciences and Technologies. Zanjan University, Zanjan, Iran, pp: 205-208.

Kraft, J.M., Burke, D.W., Haglund, W.A. 1981. Fusarium diseases of beans, peas, and lentils. In: P.E. Nelson, T.A. Toussoun, R.J. Cook (eds). Fusarium: Diseases, Biology, and Taxonomy. Pennsylvania State University, University Park, PA, USA, pp. 142-56.

Letourneau, D.K., Msuku, W.A.B. 1992. Enhanced Fuusarium solani f.sp. phaseoli infection by bean fly in Malawi. Plant Dis. 76, 1253-1255.

Naseri, B. 2008. Root rot of common bean in Zanjan, Iran: major pathogens and yield loss estimates. Australas. Plant Pathol. 37, 546-551.

Naseri, B. 2013. Epidemics of Rhizoctonia root rot in association with biological and physicochemical properties of field soil in bean crops. J. Phytopathol. 161, 397-404

Naseri, B., Marefat, A. 2011. Large-scale assessment of agricultural practices affecting Fusarium root rot and common bean yield. Eur. J. Plant Pathol. 131, 179-195.

Otten, W., Gilligan, C.A. 2006. Soil structure and soilborne diseases: Using epidemiological concepts to scale from fungal spread to plant epidemics. Eur. J. Soil Sci. 57, 26-37.

Papavizas, G.C., Lewis, J.A., Abd-El Moity, T.H. 1982. Evaluation of new biotypes of Trichoderma harzianum for tolerance to benomyl and enhanced biocontrol capabilities. Phytopathology. 72, 126-132.

Richardson, L.T. 1973. Adaptive tolerance of Fusarium solani to benzimidazole derivatives in vitro. Can. J. Bot. 51, 1725-1732.
Sanogo, S., Yang, X.B. 2001. Relation of sand content, $\mathrm{pH}$, and potassium and phosphorus nutrition to the development of sudden death syndrome in soybean. Can. J. Plant Pathol. 23, 174-180.

Scherm, H., Yang, X.B., Lundeen, P. 1998. Soil variables associated with sudden death syndrome in soybean fields in Iowa. Plant Dis. 82, 1152-1157.

Schuerger, A.C., Mitchell, D.J. 1992. Effects of temperature, hydrogen ion concentration, humidity, and light quality on disease caused by Fusarium solani f.sp. phaseoli in mung bean. Can. J. Bot. 70, 1798-1808.

Slatni, T., Krouma, A., Aydi, S., Chaiffi, C., Gouia, H., Abdelly, C. 2008. Growth, nitrogen fixation and ammonium assimilation in common bean (Phaseolus vulgaris $\mathrm{L}$ ) subjected to iron deficiency. Plant Soil. 312, 49-57.

Sullivan, P. 2001. Sustainable management of soilborne plant diseases. USDA's Rural Business Cooperative Service, USA.

Tu, J.C. 1992. Management of root rot diseases of peas, beans and tomatoes. Can. J. Plant Pathol. 14, 92-99.

Van Schoonhoven, A., Pastor-Corrales, M.A. 1987. Standard System for the Evaluation of Bean Germplasm. Centro Internacional de Agricultura Tropical, Cali, Colombia.

Weil, R.R., Magdoff, F. 2004. Significance of soil organic matter to soil quality and health. In: F. Magdoff, R. Weil (eds). Soil Organic Matter in Sustainable Agriculture. CRC, Boca Raton, FL, USA, pp: $1-44$.

Weller, D.M., Raaijmakers, J.M., McSpadden, Gardener, B.B., Thomashow, L.S. 2002. Microbial populations responsible for specific soil suppressiveness to plant pathogens. Ann. Rev. Phytopathology. 40, 309-348. 